\title{
Vegetation Response to Climate Change in the southern part of Qinghai-Tibet Plateau at Basinal Scale
}

\author{
LIU Xiaolin $^{1,2}$, LIU Chaoqun ${ }^{1,2}$, KANG Qing $^{1,2}$, YIN Bin $^{1,2}$ \\ 1. Soil and Water Conservation Monitoring Center of Pearl River Basin, Pearl River Water Resources Commission of the Ministry of \\ Water Resources, Guangzhou 510611, China; \\ 2. Pearl River Hydraulic Research Institute, Pearl River Water Resources Commission of the Ministry of Water Resources, \\ Guangzhou 510611, China
}

KEY WORDS: NDVI, Vegetation, Climate Change, the Qinghai-Tibet Plateau

\begin{abstract}
:
Global climate change has significantly affected vegetation variation in the third-polar region of the world - the Qinghai-Tibet Plateau. As one of the most important indicators of vegetation variation (growth, coverage and tempo-spatial change), the Normalized Difference Vegetation Index (NDVI) is widely employed to study the response of vegetation to climate change. However, a long-term series analysis cannot be achieved because a single data source is constrained by time sequence. Therefore, a new framework was presented in this paper to extend the product series of monthly NDVI, taking as an example the Yarlung Zangbo River Basin, one of the most important river basins in the Qinghai-Tibet Plateau. NDVI products were acquired from two public sources: Global Inventory Modeling and Mapping Studies (GIMMS) Advanced Very High Resolution Radiometer (AVHRR) and Moderate-Resolution Imaging spectroradiometer (MODIS). After having been extended using the new framework, the new time series of NDVI covers a 384 months period (1982-2013), 84 months longer than previous time series of NDVI product, greatly facilitating NDVI related scientific research. In the new framework, the Gauss Filtering Method was employed to filter out noise in the NDVI product. Next, the standard method was introduced to enhance the comparability of the two data sources, and a pixelbased regression method was used to construct NDVI-extending models with one pixel after another. The extended series of NDVI fit well with original AVHRR-NDVI. With the extended time-series, temporal trends and spatial heterogeneity of NDVI in the study area were studied. Principal influencing factors on NDVI were further determined. The monthly NDVI is highly correlated with air temperature and precipitation in terms of climatic change wherein the spatially averaged NDVI slightly increases in the summer and has increased in temperature and decreased in precipitation in the 32 years period. The spatial heterogeneity of NDVI is in accordance with the seasonal variation of the two climate-change factors. All of these findings can provide valuable scientific support for water-land resources exploration in the third-polar region of the world.
\end{abstract}

\section{INTRODUCTION}

Vegetation, as the most important component of terrestrial ecosystems, fundamentally regulates the energy budget, water cycle and biogeochemical cycle in the land surface through photosynthesis, respiration, transpiration, surface albedo, and roughness (Chen et al. 2014; Randerson et al. 2008). Vegetation's growth is strongly influenced by climate change (Goetz et al. 2005; Myneni et al. 1997; Peng et al. 2011; Shilong et al. 2010; Zhou et al. 2001). Climate change plays a key role in driving vegetation dynamics at both global and regional scales (Braswell et al. 1997; Nemani et al. 2003; Nezlin et al. 2005; Wolfgang et al. 2002; Zeng and Yang 2009). Because the terrestrial eco-environment has worsened and climate changes have increased rapidly in recent years, responses of vegetation to climate change have become increasingly important (Cannone et al. 2007; Wang et al. 2011). Vegetation is fragile and highly sensitive to changes in temperature and precipitation particularly in high elevations, cold regions and parts of arid areas in the middle and high latitudes (Diaz et al. 2003; Gottfried 1998). Therefore, vegetation dynamics and their relationship with climate variability have become a hot topic in global change studies (Huang et al. 2014; Rees et al. 2001).

The normalized difference vegetation index (NDVI), an important description of vegetation, is widely used in plant growth and plant phenology studies and is recognized, at a large regional scale, to be an important indicator of ecological conditions (Weishou et al. 2011). NDVI has been effectively used in vegetation dynamics monitoring and the study of vegetation responses to climatic changes at different scales during the past several years (Zhou et al. 2001). Using remote sensing NDVI data to investigate vegetation changes and relationships between vegetation and climate has acquired abundant achievements (Mao et al. 2012). However, there is little research focusing on the long time sequence from the 1980 s to recent years because the NDVI data sequence is relatively short and based on only one type of data source in its analyses.

At present, there are various remote sensing NDVI datasets: MODIS NDVI, AVHRR NDVI, SPOT VGT NDVI, and TM NDVI. These datasets are from different sensors and have different resolutions and time sequences. For example, the time sequence of AVHRR GIMMS NDVI is from 1982 to 2006, whereas that of MODIS NDVI is from 2000 to the present time. Single data sources are too short for the study of vegetation response to climate change, and a long-term series analysis cannot be achieved. Because AVHRR NDVI and MODIS NDVI have a number of similar characters, and the MODIS dataset requires updating, developing a method that combines traditional NDVI-AVHRR datasets used to monitor vegetation dynamics with new MODIS data is necessary (Gitelson and Kaufman 1998). For the two NDVI datasets, their spectral differences and consistency have been discussed in many studies (Brown et al. 2006; Fensholt et al. 2009; Tucker et al. 2005). At the same time several approaches have been adopted to combine data from different sensors (Steven et al. 2003). Those methods can be divided into two groups: one based on 
the spectral mechanism creating simple linear equations to transform NDVI data from one sensor to another, the other based on the remote sensing product analyzing NDVI data and constructing an integrating method, such as neural networks and the linear regression method. A per-pixel unary linear regression model was used to construct a NDVI time-series from AVHRR and MODIS by Mao (2012). However, clouds, snow, and other effects such as atmospheric aerosols in the remote sensing may obscure vegetation information, and a perpixel unary linear regression model that does not consider these factors may introduce errors into the result. Therefore, before the per-pixel unary linear regression model was used to integrate AVHRR NDVI and MODIS NDVI, an asymmetric gaussian filter method was adopted to smoothly filter the NDVI process and minimize the error in our study.

As the third-polar region of the world, the Qinghai-Tibet Plateau has attracted extensive research worldwide. The plateau has experienced substantial warming in recent decades (Liu and Chen 2000; Zhang et al. 2014), and this warming is predicted to continue in the 21 st century (Gray 2007). Previous research has revealed recent vegetation changes potentially induced by climate change in the Qinghai-Tibet Plateau (Junhui and Jix 2009; Wei et al. 2003; XU et al. 2008). The Yarlung Zangbo River Basin, located in the southern region of the Qinghai-Tibet Plateau, has special terrestrial ecosystems that are extremely sensitive to global climate change (Guo et al. 2014; Song et al. 1998). The basin's ecological effects have long been one of the research hot spots in the field of global change (Anyamba and Tucker 2005; Raynolds et al. 2006). Thus, the study of vegetation change and the relationship between NDVI and climatic parameters in this area is of significance. A number of articles regarding vegetation responses to climatic changes based on NDVI time series data in this region have been published (Guo et al. 2014; XU et al. 2013). However, those studies have short research duration based on one remote sensing data source. Are there any differences with those results during a longer time sequence? Thus far, in order to discover the vegetation responses' rules to climatic changes in the Yarlung Zangbo River basin, long-term series analyses on NDVI and the relationships between NDVI and climatic parameters are needed.

The content of this study is (i) to construct a long-term NDVI time-series from 1982-2013 in the Yarlung Zangbo River basin by integrating AVHRR GIMMS NDVI and MODIS NDVI; (ii) to present the linear trends of vegetation, temperature, and precipitation using the constructed NDVI and investigate their relationship in the growing season and in different seasons during 1982-2013 for discovering how the vegetation responses to climate changes; and (iii) to make a comparison about the correlation of NDVI-temperature and NDVI-precipitation for finding which factor is the determined to vegetation changes.

\section{DATA AND METHODS}

\subsection{Study area}

The Yarlung Zangbo River basin is located in the southern region of the Qinghai-Tibet Plateau $\left(28^{\circ} 00^{\prime}-31^{\circ} 16^{\prime} \mathrm{N}, 82^{\circ} 00^{\prime}-\right.$ $\left.97^{\circ} 07^{\prime} \mathrm{E}\right)$ between the Gangdese-Nyainqentanglha Mountains and the Himalayan Mountains, covering an area of $242,000 \mathrm{~km}^{2}$. It originates from a glacier at an elevation of 5,590 meters and flows through Pasighat of China to India. This river is the highest river in the world with an average elevation of more than 4,000 meters (Figure. 1).

In the Yarlung Zangbo River basin, the climate types are mainly alpine temperate semiarid, plateau temperate semiarid, mountain subtropical and tropical from the upper to lower basins because of the complicated topography and large altitude difference (ranging from 147 meters to 7,261 meters). The mean annual precipitation varies from $200 \mathrm{~mm}$ in the upper reaches to $5,000 \mathrm{~mm}$ in the easternmost part of the Yarlung Zangbo River basin with the peak occurring in periods from June to September ( $\mathrm{Li}$ et al. 2013). The mean annual air temperature is $5.92^{\circ} \mathrm{C}$ in the whole basin ranging from $-20 \mathrm{C}^{\circ}$ in the upper reaches to $40^{\circ} \mathrm{C}$ in the lower reaches (You et al. 2007). The river basin can be divided into three ecological regions: the upper, middle, and lower reaches of the river (Figure 1). Differences in climatic factors (particularly precipitation and temperature) create large environmental differences among the three regions of the river basin (Shen et al. 2012).

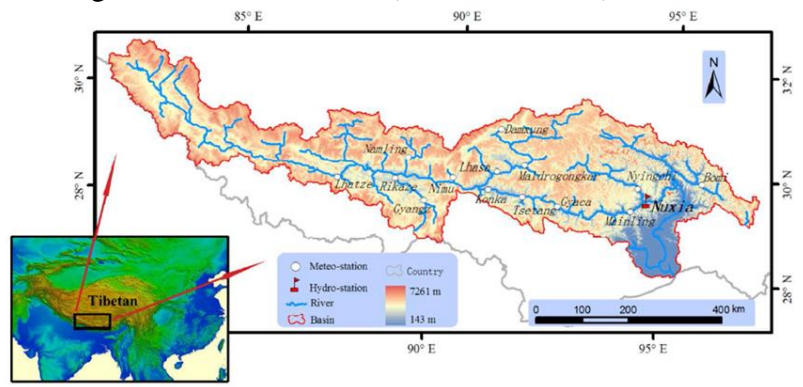

Figure 1. River network and locations of the Yarlung Zangbo River basin in the Southern Tibetan Plateau

\subsection{Dataset}

The GIMMS AVHRR NDVI and MODIS NDVI datasets were used in this study. The GIMMS NDVI datasets are based on NOAA's meteorological satellite data and produced by the Global Inventory Modeling and Mapping Studies composites at a spatial resolution of $8 \mathrm{~km} \times 8 \mathrm{~km}$ and 15 -d interval (Tucker et al. 2005). The GIMMS NDVI datasets were corrected to minimize the effects of volcanic eruptions, solar angles and sensor errors and shifts. The monthly GIMMS NDVI dataset from 1982 to 2006 was obtained using the Maximum Value Composite (MVC) method. The monthly MODIS NDVI datasets were obtained from NASA's Earth Observing System from 2000 to 2013 at a spatial resolution of $1 \mathrm{~km} \times 1 \mathrm{~km}$. The two datasets have the same time series from 2000 to 2006 . The regional data that cover the study area were extracted by ENVI software.

The information on the distribution of vegetation types was obtained from a vegetation map of China with a scale of 1:1,000,000 digitized by the China Vegetation Editing Committee, Institute of Geography of the Chinese Academy of Sciences. The vegetation in the Yarlung Zangbo River was classified into five types: forest, grassland, shrub, alpine vegetation, cultural vegetation. The meteorological data from 1982 to 2013 were acquired from the National Meteorological Center of China, including monthly precipitation and monthly mean temperature. The data include findings from 27 meteorological stations distributed in and around the Yarlung Zangbo River. The distribution of different types of vegetation and meteorological stations are shown in Figure 2. 
The ENVI4. 8 image processing, ArcGIS-10.2 and TIMESAT 3.1 software (Jönsson and Eklundh 2004) were used for data processing. To eliminate the effects of nonvegetation factors on AVHRR GIMMS NDVI and MODIS NDVI, such as aerosol, snow and ice, the solar illumination angle, and the sensor observation angle of view, the asymmetric gaussian filters method (Eq. 1) was applied to smooth filter process the NDVI.

$$
g\left(t ; x_{1}, x_{2}, \ldots, x_{5}\right)=\left\{\begin{array}{l}
\exp \left[-\left(\frac{t-x_{1}}{x_{2}}\right)^{x_{3}}\right] \quad \text { if } t>x_{1} \\
\exp \left[-\left(\frac{x_{1}-t}{x_{4}}\right)^{x_{5}}\right] \text { if } t<x_{1}
\end{array}\right.
$$

For this function $x_{1}$ determines the position of the maximum of minimum with respect to the independent time variable $t$, while $x_{2}$ and $x_{3}$ determine the width and flatness (kurtosis) of the right function halt. Similarly, $x_{4}$ and $x_{5}$ determine the width and flatness of the left half.

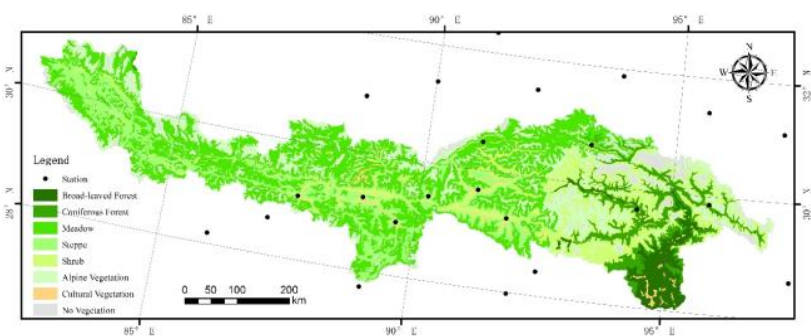

Figure 2. Vegetation types and meteorological stations in the Yarlung Zangbo River basin

After filtering, the MODIS NDVI data were resampled to a 8 $\mathrm{km} \times 8 \mathrm{~km}$ resolution by the nearest neighbor method to match the AVHRR GIMMS data because the two datasets were from different remote sensors and had different spectrum responses to vegetation. We constructed the monthly NDVI sequence from 1982 to 2013 using the per-pixel unary linear regression model based on the monthly NDVI data of the two datasets from 2000 to 2006 as proposed by Mao et al. (2012). The new 2000-2013 NDVI was designated the expanded NDVI. Next, the consistency of the two datasets and the accuracy of the constructed long-term NDVI time series were checked by several statistical and correlation analyses. The per-pixel unary linear regression model structure is as follows:

$$
b=\frac{\sum_{i=1}^{n}\left(G_{i}-\bar{V}\right)\left(G_{i}-\bar{G}\right)}{\sum_{i=1}^{n}\left(V_{i}-\bar{V}\right)^{2}} \quad a=\bar{G}-b \bar{V}
$$

$G_{i}$ represents GIMMS NDVI in the $i$ th month, while $V_{i}$ is MODIS NDVI $(8 \mathrm{~km} \times 8 \mathrm{~km})$ in the $i$ th month. Parameters, $a$ and $b$, are estimated by the least square method, with $\varepsilon_{i}$ as random error.

To study the vegetation response to climate change in the Yarlung Zangbo River, we selected temperature and precipitation as the primary climate factors and calculated the spatially averaged NDVI, mean temperature, and total precipitation every year for the Yarlung Zangbo River. Because summer (July-September) is the best season for vegetation growth, especially in Yarlung Zangbo River. The summer mean NDVI represents the best plant growth. Thus, the NDVI, temperature and precipitation were calculated in summers as well as years. Next, mean monthly NDVI, temperature, and precipitation for different months in the 32 years. Then the linear time trend was estimated by regressing it as a function of time from 1982 to 2013 based on the yearly and monthly data. Meanwhile, the correlations between monthly NDVI and climatic factors were analyzed. To further investigate the spatial distribution of the trends of yearly NDVI, linear trends from 1982 to 2013 on a per-pixel basis were examined.

To analyze the vegetation response to climate changes by season, correlations between NDVI and temperature and precipitation were calculated for the four seasons. Next, we analyzed the correlations in the different regions of the Yalung Zangbo River Basin for finding how the vegetation responses to the climate changes in the whole basin.

To investigate which climate factor plays a major role in influencing different vegetation, the analysis of the relationships between monthly NDVI and climatic parameters were performed based on stations. We extracted the NDVI time series for each meteorological station from the mean of $3 \times 3$ pixels around the location of the stations and calculated the correlation coefficient between NDVI and monthly mean temperature and monthly precipitation for each station in the study area.

\section{RESULTS}

\subsection{Precision validation}

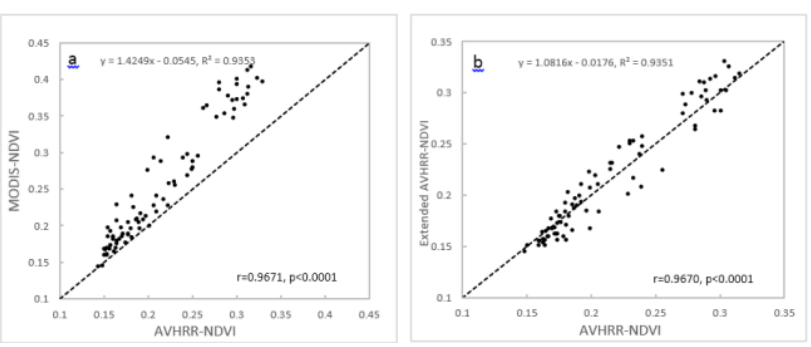

Figure 3. Results of precision validation by spatial mean data: (a) original data; (b) extended data

For the applications focusing on vegetation responses to climatic changes, the continuity and consistency of the two NDVI datasets are essential (Steven et al. 2003). The MODIS NDVI and AVHRR GIMMS NDVI data are from different sensors such that they have different spectral and spatial resolutions. The precision validation of expanded NDVI from 2000 to 2013 is indispensable. The contrast of the AVHRR NDVI and MODIS NDVI from 2000 to 2006 in the monthly spatially averaged NDVI is shown in Fig. 3a. The correlation coefficient was $0.9671(\mathrm{p}<0.0001)$, but the relative error was 0.4249 . The contrast of the AVHRR NDVI and the extended NDVI is shown in Fig. $3 b$. The correlation coefficient was the same as before; however the relative error decreased to 0.0816 . The extended NDVI is almost same as the AVHRR NDVI, so the NDVI that combines AVHRR and MODIS could well describe the vegetation changes feature in the Yarlung Zangbo River basin.

\subsection{Vegetation change and correlation analyses}

3.2.1 Trends of spatially averaged yearly/summer NDVI and temperature/precipitation of climatic parameters: The annual NDVI, precipitation and temperature in the Yarlung Zangbo River Basin from 1982 to 2013 are shown in Figure 4. NDVI and temperature are the yearly average values for each year, while precipitation is the total value for each year. The NDVI showed an obvious increasing trend, with a rate of 
0.008/10a (Figure 4a). The annual precipitation slightly increased over the past 32 years, the rate is $11.42 \mathrm{~mm} / 10 \mathrm{a}$ (Figure 4b). However, air temperature has significantly increased over the past 32 years with a rising rate of $0.61 / 10 \mathrm{a}$ (Figure 4c).

Summer is the best season for vegetation growth, especially south of the Qinghai-Tibet Plateau, due to the relatively high temperatures and high levels of precipitation. Considering the seasonal feature of vegetation in the Qinghai-Tibet Plateau, we investigated the summer NDVI variation in the 32 years. The spatially averaged NDVI exhibited a slight increasing trend. The temperature exhibited an upward trend, whereas precipitation had a stable trend (Figure. 5). In terms of coarse scale, no significant correlations between summer NDVI and temperature or precipitation were found over the 32 years. However, the combined influence on NDVI was evident from the variation curves. NDVI increased when temperature and precipitation rose, such as observed in 1991 and 2003. NDVI decreased with reduced temperature and precipitation in 1997. When trends of temperature and precipitation differed, the NDVI of a given year exhibited a minimal variation.

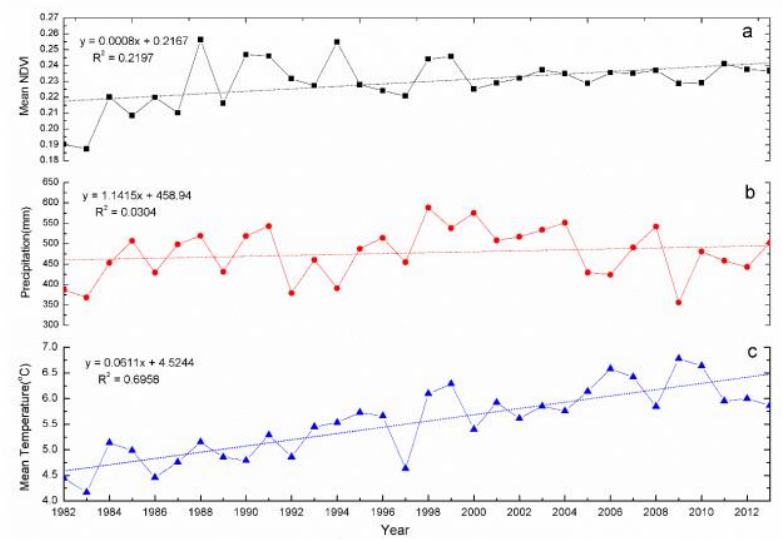

Figure 4. Changes of annual NDVI, precipitation and temperature from 1982 to 2013 in the Yalung Zangbo River Basin

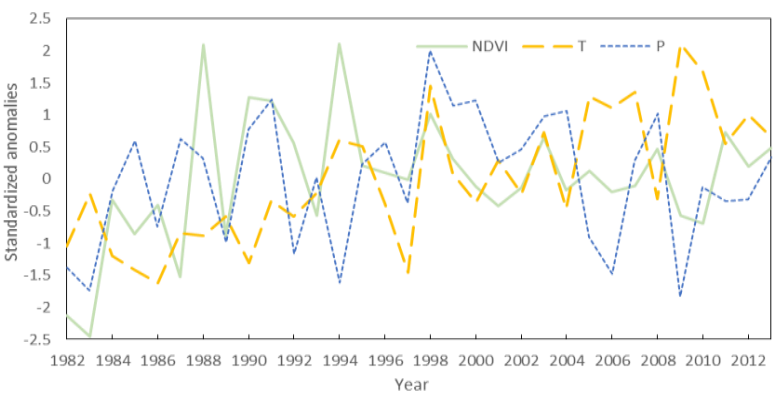

Figure 5. Trends in the mean NDVI and mean temperature and total precipitation in summer from 1982 to 2013

3.2.2 Trends of monthly NDVI, temperature and precipitation: The magnitude of the monthly NDVI and its change over time are important indicators of the contribution of vegetation activity in different months to total annual plant growth (Piao et al. 2003). In the Qinghai-Tibet Plateau, the mean monthly NDVI reached maximum values in August. From December to April, the mean monthly NDVI was low (Figure 6a). The mean NDVI value in August was 0.431. In the 32 years studied, the trends of monthly NDVI showed positive values from January to August, and negative values from September to December. The maximum trend value was observed in July, and the minimum was observed in October. The NDVI trends and their patterns were coupled with those of climatic variables (Figure $6 \mathrm{~b}$ and $\mathrm{c}$ ). Monthly temperature and precipitation showed a pattern similar to that of NDVI: a higher value was observed in summer and a lower value in winter. However, the highest mean temperature and precipitation was in July instead of August, the month with the largest mean NDVI. The monthly temperature trends were positive over the year-long course of the study period. The largest temperature rise occurred in January with an annual rate of $0.083{ }^{\circ} \mathrm{C}$, indicating that temperature in this month increased by $2.66{ }^{\circ} \mathrm{C}$ relative to 1982 . The monthly precipitation showed negative trends in January, April, September and December. The largest precipitation decrease occurred in September, with an annual rate of -0.26 $\mathrm{mm}$, indicating that precipitation during this month decreased by $8.4 \mathrm{~mm}$ from 1982 to 2013 .

The correlation between monthly climatic variables and NDVI is shown in Figure 6d. A positive correlation between temperature and NDVI was observed for most of months. NDVI significantly correlated with temperature ( $1 \%$ level) only in the spring. This result confirms that increasing temperature improves vegetation growth in spring in the whole region. The relationship between precipitation and NDVI was complicated: significantly positive correlations were observed in the autumn (May to July), no significantly positive correlations occurred for February and August, and negative correlations were discovered for other months. This means that precipitation in autumn contribute to vegetation growth in the Yarlung Zangbo River Basin.
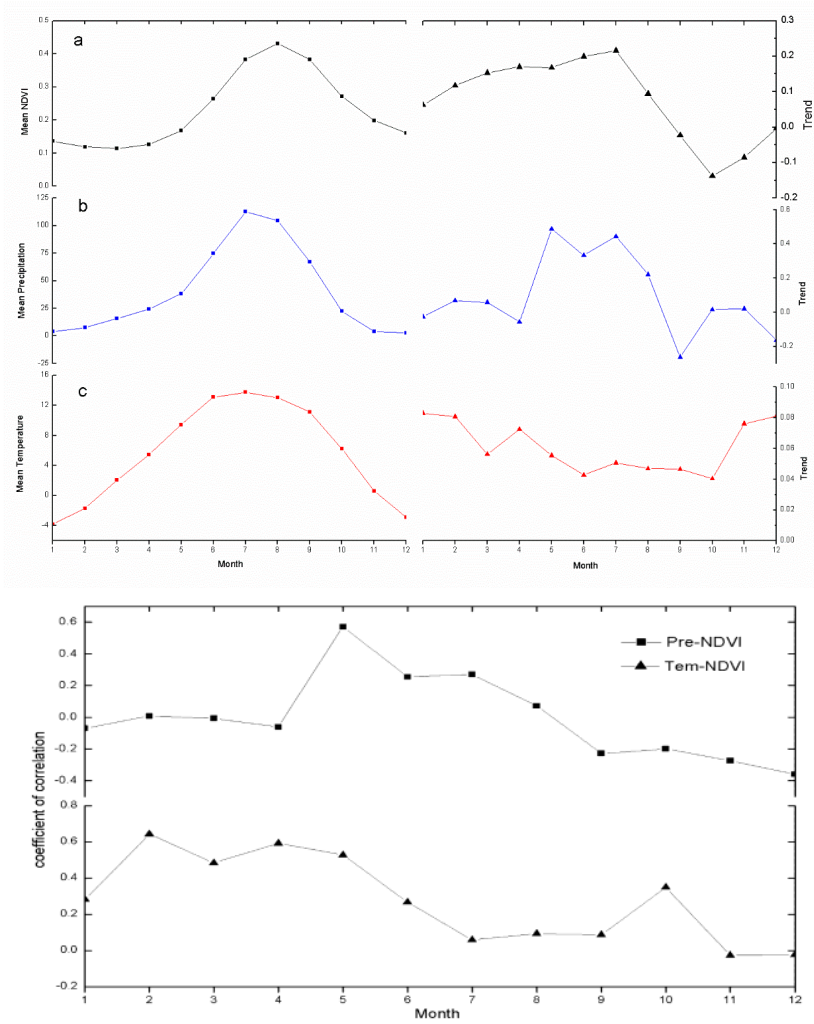

Figure 6. Seasonal changes in monthly NDVI and climatic variables from 1982 to 201 in the Yarlung Zangbo River. (a) 32-Year averaged monthly NDVI and its trend; (b) 32-year averaged monthly mean temperature and its trend; (c) 32-year averaged monthly precipitation and its trend; (d) correlations between monthly NDVI and temperature and precipitation. 
3.2.3 Linear trends of NDVI from 1982 to 2013 on a perpixel basis: Although the trends in monthly NDVI were complicated and exhibited no significantly increasing trend in summer, we found a high degree of spatial heterogeneity on per-pixel analysis (Figure 7). The pixels that showed remarkable increasing trends were mainly distributed in the middle basin. The increasing trend was about $0.003 /$ year. The dominant vegetation type is steppe and meadow. The pixels showing moderate increasing trends were mainly in up basin. Grassland and marsh are main vegetation types in these areas. The areas that showed decreasing NDVI showed a changing trend about $-0.003 /$ year, observed mainly in forest dominated regions, including middle and down basin.

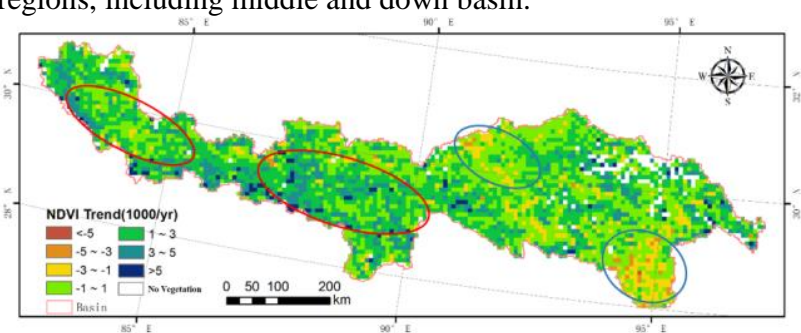

Figure 7. Spatial pattern of NDVI trends from 1982 to 2013

3.2.4 Spatial pattern of the correlations between seasonal NDVI and temperature/precipitation: To analyze the effects of regional climatic changes on seasonal NDVI, correlations between NDVI and temperature and precipitation were investigated for four seasons. In the spring, NDVI was positively correlated with temperature in most areas (Figure 8a), suggesting the possible effects of temperature on spring NDVI for most parts of the Yarlung Zangbo River. There was a positive correlation between NDVI and precipitation in the middle river area in the spring (Figure 8b), but a negative correlation was observed in the upper and lower river areas.

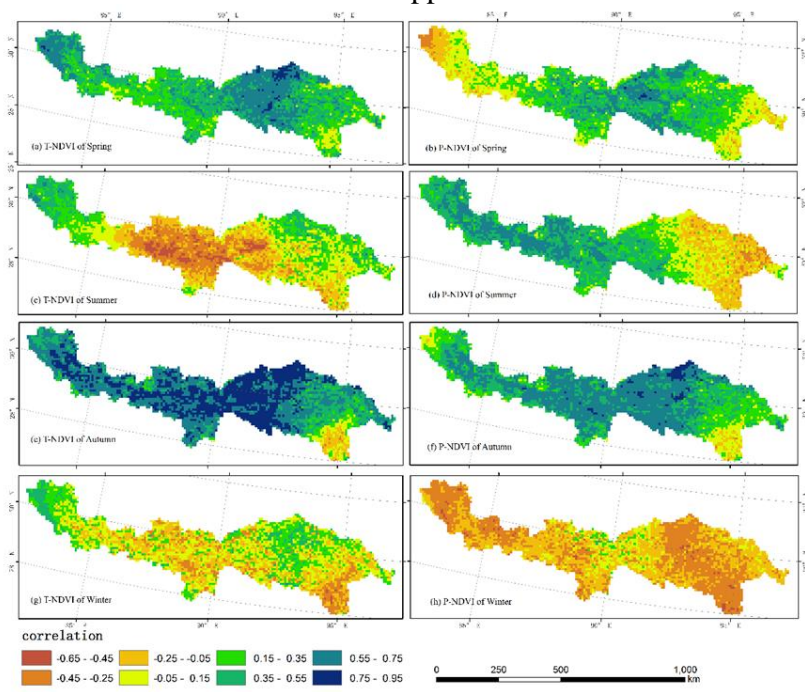

Figure 8. Spatial pattern of correlation between NDVI and temperature and precipitation for spring (March-May, a and b), summer (June-October, c and d), autumn (September-

November, e and f), and winter (December-February, $g$ and $h$ ).

In the summer, a negative correlation between NDVI and temperature was observed in most areas, being primarily distributed in the middle basin; positive correlations were observed between NDVI and temperature in other areas of the study region (Figure 8c). A significantly positive correlation between NDVI and precipitation was found in the upper basin, where the vegetation type is mainly steppe and meadow, and a negative correlation between NDVI and precipitation was found in forest areas, down river (Figure 8d).

In the autumn (Figure 8e and $\mathrm{f}$ ), a significantly positive correlation between NDVI and temperature and precipitation was detected in most areas of the study region. A negative correlation between NDVI and temperature and precipitation was observed within the downstream boundary, where air temperatures are high, precipitation is sufficient and vegetation is thick.

In the winter, the distribution of correlation between NDVI and temperature is complicated (Figure 8g), but a significant negative correlation between NDVI and precipitation was observed in the entire basin (Figure $8 \mathrm{~h}$ ).

\subsection{Correlations between monthly NDVI and temperature/precipitation based on meteorological stations}

The calculated correlation coefficients between monthly NDVI and temperature (CNT) indicated a highly significant correlation between NDVI and temperature for all meteorological stations in the Yarlung Zangbo River. For all stations, the correlation was highly significant at the 0.01 level. Among these stations, the Bomi station showed a minimum correlation, with a CNT of 0.62 over the 32 -year period. The maximum value was 0.87 at the Jiali station. The average CNT for the 15 meteorological stations was 0.744 . The correlation coefficients between monthly NDVI and precipitation (CNP) showed a significant correlation at the 0.01 level for all meteorological stations except the Bomi station. Most CNP values were greater than 0.7. The mean CNP for all stations was 0.709 , and one station showed the maximum CNP at 0.84 . The minimum CNP observed at the Bomi station was 0.15 .

\section{DISCUSSION}

\subsection{Integrated application of two remote sensing datasets}

Given the limitations presented by a single NDVI dataset in time sequence, the integrated application of two remote datasets is important. In this paper, the two datasets were obtained from different sensors. The difference value between MODIS NDVI and AVHRR NDVI in most pixels was about 0.1. In the regional scale, Xin et al. (2007) extended the regional averaged AVHRR NDVI in the Loess Plateau of China, using SPOTVGT NDVI by unary linear regression equation to study annual variation trends. They also performed construction on pixel extent. Although they determined that accuracy in pixel integration could not be used in analysis, they provided a good idea for constructing NDVI time series and conducting consistency checks. With regard to pixel extent, Brown et al. (2008) constructed continuous NDVI time series from AVHRR and MODIS data using neural networks. They obtained accurate results, in which many influencing factors were taken into consideration. On the basis of these previous studies, this paper constructed NDVI time series using per-pixel unary linear regression equation and conducted a consistency check. Using this method, the pixels generated minimal exceptional values, which can be disregarded. According to the results, the constructed NDVI time series in this study passed the consistency check. Therefore, it can be used in trend and correlation analyses. The integrated application of the two different remote sensing datasets is an effective method for use in the correlation analysis of vegetation and climatic variables. 


\subsection{Comparison of NDVI change trends with other NDVI studies}

The monthly NDVI showed obvious variations during the growing season (April-October). Monthly climatic changes and trends in the 32 years provided a clear illustration of the NDVI trends. Piao et al. (2003) obtained national-scale results for the monthly NDVI changes and trends from 1982 to 1999 . They found that the maximum NDVI occurred in August; however, monthly NDVI showed positive values for all months. The difference in their results from ours is attributed to the longer study period and the relatively small scale of the present research. The unchanged increase in NDVI in August and September was attributed to the influence of time lag, the widely distributed river, and the relatively adequate precipitation for vegetation growth in Northeast China (Song and $\mathrm{Ma}, 2008)$. The increased temperature antedated the vegetation growing season (Piao et al., 2004), which yielded the interpretation of the positive NDVI trend in spring. Guo et al (2008) found slowly decreasing NDVI trend by investigating NDVI changes in Northeast China from 1982 to 2003. Differently, results of this paper had obviously change trends pattern. More obviously special heterogeneity in accordance with terrain showed during 1982-2013.

\subsection{Correlation between NDVI and climatic variables}

Negative correlation between NDVI and temperature in spring and winter was attributed to low temperature, which stemmed at least in part from the snow-covered and frozen ground. These areas had low vegetation under snow or no vegetation at all because of the low temperature. The region of the boundary of basin showed negative correlation between NDVI and precipitation because spring is cold and snowy in these areas. Precipitation causes more clouds to appear and then reduces incident radiation. Limited incident radiation hinders photosynthesis, which is essential for vegetation growth (Song and Ma, 2008). In summer, the negative correlation between NDVI and temperature in arid areas of middle basin and most areas of Lasa basin can be explained by the limited vegetation growth caused by increased temperature and fewer precipitations. Increasing temperature enhanced the intensity of transpiration, and the decreasing precipitation reduced the available moisture for plants (Yang et al., 2009). Nevertheless, positive correlations between NDVI and temperature in other areas of the study region resulted from the increased temperature, which enhanced photosynthesis and respiration for plant growth. The significantly positive correlation between NDVI and precipitation in the up grasslands was caused by the precipitation which provided the required moisture for vegetation growth. Precipitation in summer benefited vegetation growth in arid areas. In forest dominated areas, where abundant summer rainfall occurs, a negative correlation between NDVI and precipitation was caused possibly by the increased precipitation accompanied by an increase in cloud cover. Thus, a reduction in incoming solar radiation also occurred. There had obvious seasonal fluctuation in the Yarlung Zangbo Rive Basin driven by climatic changes. Comparing NDVI changes in the four seasons, in summer, vegetation NDVI had the largest change and the correlation between NDVI and climatic factors was remarkable.

\subsection{Effects of vegetation type on CNT and CNP}

To avoid the influence of integrated raster climatic data on the correlation of various elevations, station-based analyses were performed. The correlation analysis for monthly NDVI and climatic parameters for stations showed that CNT was larger than the CNP. For $80 \%$ of all stations (12 of the 15), CNT was higher than CNP. The average CNT and CNP were 0.863 and 0.729 , respectively. The effect of temperature on vegetation NDVI was stronger than that of precipitation in the entire region. This result was comparable with conclusions drawn by Wang et al. (2002), who used pixel statistics for the Yarlu Zangbo River Basin. Those stations where CNT was lower than $\mathrm{CNP}$ are distributed mainly in down basin.

\section{CONCLUSIONS}

This study constructed the monthly NDVI sequences of the Yarlung Zangbo River basin covering the years 1982 to 2013 using the per-pixel unary linear regression model based on monthly NDVI data of MODIS and AVHRR datasets. The data were comprehensively used in the analyses of the correlation between NDVI and climatic parameters. This study confirmed the feasibility of long-term NDVI time series climate research.

In the 28-year period, monthly NDVI was closely correlated with climate variations. NDVI trends were spatially heterogeneous, corresponding with regional climatic characteristics for different seasons. Spatially averaged NDVI in the summer exhibited a stable trend in 1982 to 2013, with increased temperature and slightly decreased precipitation. Yearly maximum NDVI trends reflected an obvious spatial pattern for different regions and different vegetation types. The NDVI of all meteorological stations had significant correlations with monthly mean temperature and monthly precipitation from 1982 to 2013. The correlation coefficient between NDVI and temperature was larger than that between NDVI and precipitation in most of the stations and for all vegetation types. Different vegetation types exhibited different spatial responses to climatic changes.

\section{ACKNOWLEDGEMENTS}

We acknowledge all reviewers and editors for their valuable advice on improving the quality of this paper. This research was supported by Estimation and Forecast of Suspended Sediment Concentration in the Pearl River Estuary from Remote Sensing Images based on Data Assimilation Algorithm (Natural Science Foundation of Guangdong, China, NO. 2017A030313232), Remote Sensing Identification and Dynamic Monitoring of Urban Black-Odor Water Bodies based on Chroma Parameters: A Case Study in Guangzhou (Science and Technology Program of Guangzhou, China, NO. 201804010270)

\section{REFERENCES}

Anyamba, A., \& Tucker, C.J. (2005). Analysis of Sahelian vegetation dynamics using NOAA-AVHRR NDVI data from 1981-2003. Journal of Arid Environments, 63, 596-614

Braswell, B.H., Schimel, D.S., Linder, E., \& Moore, B. (1997). The response of global terrestrial ecosystems to interannual temperature variability. Science, 278, 870-872

Brown, M.E., Pinzon, J.E., Didan, K., Morisette, J.T., \& Tucker, C.J. (2006). Evaluation of the consistency of long-term NDVI time series derived from AVHRR, SPOT-vegetation, SeaWiFS, MODIS, and Landsat ETM+ sensors. IEEE Transactions on 
Geoscience \& Remote Sensing, 44, 1787-1793

Cannone, N., Sgorbati, S., \& Guglielmin, M. (2007). Unexpected impacts of climate change on alpine vegetation. Ecosystems, 5, 360-364

Chen, B., Xu, G., Coops, N.C., Ciais, P., Innes, J.L., Wang, G., Myneni, R.B., Wang, T., Krzyzanowski, J., \& Li, Q. (2014). Changes in vegetation photosynthetic activity trends across the Asia-Pacific region over the last three decades. Remote Sensing of Environment, 144, 28-41

Diaz, H.F., Grosjean, M., \& Graumlich, L. (2003). Climate variability and change in high elevation regions: Past, present and future. Climatic Change, 59, 1-4

Fensholt, R., Rasmussen, K., Nielsen, T.T., \& Mbow, C. (2009). Evaluation of earth observation based long term vegetation trends - Intercomparing NDVI time series trend analysis consistency of Sahel from AVHRR GIMMS, Terra MODIS and SPOT VGT data. Remote Sensing of Environment, 113, 18861898

Gitelson, A.A., \& Kaufman, Y.J. (1998). MODIS NDVI Optimization To Fit the AVHRR Data Series-Spectral Considerations. Remote Sensing of Environment, 66, 343-350

Goetz, S.J., Bunn, A.G., Fiske, G.J., \& Houghton, R.A. (2005). Satellite-observed photosynthetic trends across boreal North America associated with climate and fire disturbance. Proceedings of the National Academy of Sciences of the United States of America, 102, 13521-13525

Gottfried, M. (1998). Prediction of Vegetation Patterns at the Limits of Plant Life: A New View of the Alpine-Nival Ecotone. Arctic \& Alpine Research, 30, 207-221

Gray, V. (2007). Climate Change 2007: The Physical Science Basis. Summary for Policy Makers. International Panel on Climate Change Fourth Assessment Report Ipcc Secretariat, 54 , 44-45

Guo, B., Zhou, Y., Wang, S.-x., \& Tao, H.-p. (2014). The relationship between normalized difference vegetation index (NDVI) and climate factors in the semiarid region: A case study in Yalu Tsangpo River basin of Qinghai-Tibet Plateau. Journal of Mountain Science, 11, 926-940

Huang, C., Li, Y., Liu, G., Zhang, H., \& Liu, Q. (2014). Recent climate variability and its impact on precipitation, temperature, and vegetation dynamics in the Lancang River headwater area of China. International Journal of Remote Sensing, 35, 28222834

Jönsson, P., \& Eklundh, L. (2004). TIMESAT — a program for analyzing time-series of satellite sensor data. Computers \& Geosciences, 30, 833-845

Junhui, L., \& Jix, G. (2009). Spatial-temporal changes of vegetation coverage and its responses to global climate changes in the Tibetan Plateau. In, Environmental Science and Information Application Technology, 2009. ESIAT 2009. International Conference on (pp. 78-82): IEEE

Li, F., Xu, Z., Feng, Y., Liu, M., \& Liu, W. (2013). Changes of land cover in the Yarlung Tsangpo River basin from 1985 to 2005. Environmental Earth Sciences, 68, 181-188
Liu, X., \& Chen, B. (2000). Climatic warming in the Tibetan Plateau during recent decades. International Journal of Climatology, 20, 1729-1742

Mao, D.H., Wang, Z.M., Luo, L., \& Ren, C.Y. (2012). Integrating AVHRR and MODIS data to monitor NDVI changes and their relationships with climatic parameters in Northeast China. International Journal of Applied Earth Observation and Geoinformation, 18, 528-536

Myneni, R.B., Keeling, C.D., Tucker, C.J., Asrar, G., \& Nemani, R.R. (1997). Increased plant growth in the northern high latitudes from 1981 to 1991. Nature, 386, 698-702

Nemani, R.R., Keeling, C.D., Hashimoto, H., Jolly, W.M., Piper, S.C., Tucker, C.J., Myneni, R.B., \& Running, S.W. (2003). Climate-driven increases in global terrestrial net primary production from 1982 to 1999 . Science, 300, 1560-1563

Nezlin, N.P., Kostianoy, A.G., \& Li, B.L. (2005). Inter-annual variability and interaction of remote-sensed vegetation index and atmospheric precipitation in the Aral Sea region. Journal of Arid Environments, 62, 677-700

Peng, S., Chen, A., Xu, L., Cao, C., Fang, J., Myneni, R.B., Pinzon, J.E., Tucker, C.J., \& Piao, S. (2011). Recent change of vegetation growth trend in China. Environmental Research Letters, 6

Piao, S.L., Fang, J.Y., Zhou, L.M., Guo, Q.H., Henderson, M., Ji, W., Li, Y., \& Tao, S. (2003). Interannual variations of monthly and seasonal normalized difference vegetation index (NDVI) in China from 1982 to 1999. Journal of Geophysical Research-Atmospheres, 108

Randerson, J.T., Canadell, J.G., Anderson, R.G., Avissar, R., Baldocchi, D.D., Bonan, G.B., Caldeira, K., Diffenbaugh, N.S., Field, C.B., \& Hungate, B.A. (2008). Protecting climate with forests. Environmental Research Letters, 3, 269-269

Raynolds, M.K., Walker, D.A., \& Maier, H.A. (2006). NDVI patterns and phytomass distribution in the circumpolar Arctic. Remote Sensing of Environment, 102, 271-281

Rees, M., ., Condit, R., ., Crawley, M., ., Pacala, S., ., \& Tilman, D., . (2001). Long-term studies of vegetation dynamics. Science, 293, 650-655

Shen, W., Liu, D., Ji, D., Shen, H., \& Lin, N. (2012). Dynamics and Driving Forces of the Alpine Wetlands in the Yarlung Zangbo River Basin of Tibet, China. In, Proceedings of World Academy of Science, Engineering and Technology: World Academy of Science, Engineering and Technology

Shilong, P., Philippe, C., Yao, H., Zehao, S., Shushi, P., Junsheng, L., Liping, Z., Hongyan, L., Yuecun, M., \& Yihui, D. (2010). The impacts of climate change on water resources and agriculture in China. Nature, 467, 43-51

Song F, Tang M, Wang D(1998). New evidence for the QinghaiXizang (Tibet) Plateau as a pilot region of climatic fluctuation in China[J]. Chinese Science Bulletin, 1998, 43(20):1745-1749.

Steven, M.D., Malthus, T.J., Baret, F., Xu, H., \& Chopping, M.J. (2003). Intercalibration of vegetation indices from different 
Tucker, C.J., Pinzon, J.E., Brown, M.E., Slayback, D.A., Pak, E.W., Mahoney, R., Vermote, E.F., \& El Saleous, N. (2005). An extended AVHRR 8-km NDVI dataset compatible with MODIS and SPOT vegetation NDVI data. International Journal of Remote Sensing, 26, 4485-4498

Wang, J., Ye, B., Liu, F., Li, J., \& Yang, G. (2011). Variations of NDVI over elevational zones during the past two decades and climatic controls in the Qilian mountains, northwestern China. Arctic, Antarctic, and Alpine Research, 43, 127-136

Wei, Z., Huang, R., Sciences, C.A.O., \& Lanzhou (2003). Interannual and Interdecadal Variations of Air Temperature and Precipitation over the Tibetan Plateau. Chinese Journal of Atmospheric Sciences, 27, 157-170

Weishou, S., Di, J., Hui, Z., Shouguang, Y., Haidong, L., \& Naifeng, L. (2011). The response relation between climate change and NDVI over the Qinghai-Tibet plateau. Journal of the World Academy of Science, Engineering and Technology, 59, 2216-2222

Wolfgang, L., I Colin, P., Myneni, R.B., Stephen, S., Pierre, F., Wolfgang, C., Philippe, B., Wolfgang, B., \& Benjamin, S. (2002). Climatic Control of the High-Latitude Vegetation Greening Trend and Pinatubo Effect. Science, 296, 1687-1689

XU, CHEN, LEVY, \& WA (2008). Spatiotemporal vegetation cover variations in the Qinghai-Tibet Plateau under global climate change. Chinese Science Bulletin, 53, 915-922

XU, Z., LIU, W., LI, F., \& LIU, P. (2013). Vegetation change and its relationship with precipitation on the southern Tibetan Plateau. Wallingford, ROYAUME-UNI: International Association of Hydrological Sciences

You, Q., Kang, S., Wu, Y., \& Yan, Y. (2007). Climate change over the Yarlung Zangbo river basin during 1961-2005. Journal of Geographical Sciences, 17, 409-420

Zeng, B., \& Yang, T.-B. (2009). Natural vegetation responses to warming climates in Qaidam Basin 1982-2003. International Journal of Remote Sensing 2009 Vol. 30 No. 21/22 pp. 5685 5701 , volume $30,5685-5701(5617)$

Zhang, G., Yao, T., Xie, H., Qin, J., Ye, Q., Dai, Y., \& Guo, R. (2014). Estimating surface temperature changes of lakes in the Tibetan Plateau using MODIS LST data. Journal of Geophysical Research: Atmospheres, 119, 8552-8567

Zhou, L.M., Tucker, C.J., Kaufmann, R.K., Slayback, D., Shabanov, N.V., \& Myneni, R.B. (2001). Variations in northern vegetation activity inferred from satellite data of vegetation index during 1981 to 1999. Journal of Geophysical ResearchAtmospheres, 106, 20069-20083 